\title{
Increasing confidence in model prediction: A case study on water quality data collation for model validation in the Great Barrier Reef catchments
}

\author{
$\underline{\text { R. Packett }}^{\mathrm{a}}$, D. Waters ${ }^{\mathrm{a}, \mathrm{b}}$ and G. McCloskey ${ }^{\mathrm{a}}$ \\ ${ }^{a}$ Department of Environment and Resource Management, Queensland, Australia, \\ ${ }^{b}$ eWater CRC, University of Canberra, Australian Capital Territory \\ Email: robert.packett@derm.gld.gov.au
}

\begin{abstract}
Reliable water quality data is critical for the calibration and validation of catchment models. Recent application of the Source Catchments water quality model across the Great Barrier Reef (GBR) catchments of north eastern Australia has highlighted the need for water quality data, especially during high flows, to reduce uncertainty and "reliance on best guess" approaches to model parameterisation and the subsequent validation of model outputs. Under the Reef Rescue program the Queensland Department of Environment and Resource Management (DERM) is required to build six catchment models to report on progress against water quality targets. A modified version of the eWater Source Catchments water quality model is being applied across the GBR region $\left(\sim 423,000 \mathrm{~km}^{2}\right)$.
\end{abstract}

A common problem for water quality modelling is a lack of data to parameterise and validate models. It is therefore important to identify and utilise data from a range of sources. If resources are available, there is also the opportunity to acquire new data to inform the modelling. This paper describes the process used for model validation across an extensive geographical area using a diverse source of data sets.

Validation data sets included the collation of historical data from the DERM ambient and event monitoring programs, recent high frequency event load monitoring data and previous modelled estimates to compare with current modelled outputs. Additional data sets used in the validation process included continuous turbidity logging data, cross sectional event sampling in combination with acoustic Doppler backscatter data, sediment sourcing to identify contributing areas in the landscape, storage trapping efficiency and concentration half lives for nutrients and pesticides in storages. Collaboration and data sharing were, and continue to be, a major part of the overall data collection and validation process. The use of analysis software such as the "Loads Tool" and the "River Analysis Package" simplified many calculations in a consistent way for comparison to model outputs.

The results from this data collation and validation process were highly variable within individual GBR catchments and across the entire GBR region. This variability in water quality and catchment condition data is not surprising given the range of geographical and climatic extremes experienced in north eastern Australia. The amount and reliability of the collated data also varied between regions; however, the combination of collating existing data and collecting new data specific to model parameterisation provided a significant improvement to the knowledge base for current and future model validation.

The data validation exercise has provided a much greater understanding of what data is available, how it can be used in the current model applications for the GBR and what new data will be required in the future to increase the confidence in model outputs.

Keywords: Source Catchments, model validation, water quality data 


\section{INTRODUCTION}

The Reef Plan and the Reef Rescue package are collaborative initiatives of the Queensland and Australian governments designed to improve the quality of water entering the Great Barrier Reef (GBR) lagoon from reef catchments (State of Queensland and Commonwealth of Australia, 2003). The program aims to assist farmers and catchment managers in reducing the amount of sediments, nutrients and pesticides in runoff to the GBR. A key component of the overall program is the application of the eWater - Source Catchments model (eWater CRC, 2010) incorporating a dynamic version of SedNet/ANNEX (Wilkinson et al., 2004) across thirty-five (of the thirty-nine) GBR catchments (Figure 1.).

The Queensland Department of Environment and Resource Management (DERM) is currently constructing models that combine GBR catchments into six natural resource management regions: Cape York, Wet Tropics, Burdekin, Mackay-Whitsundays, Fitzroy and Burnett-Mary.

The modelling project will include baseline (current condition) and improved management scenarios to identify hot spots and provide a tool for predicting the impacts of changed management practices on GBR water quality. The project is currently at the baseline phase with initial model output reporting due in the second half of 2011.

A common issue with this type of modeling exercise is the availability of suitable water quality data for model parameterisation and validation of model outputs.

A brief summary of the methods used to validate the models is outlined below; they include the collation and interpretation of historical data and the acquisition of new data to fill knowledge gaps.

\section{DATA COLLATION METHODS}

The modelled outputs that will be of most value in the current project are load estimates over a time period, for example, weeks, months or years. The modelled load estimates can then be compared to observed load estimates based on flow and parameter concentration from fieldwork or other methods.

Water quality parameters of primary interest for model validation are suspended sediments, dissolved and particulate nitrogen and phosphorus, and a number of commonly used

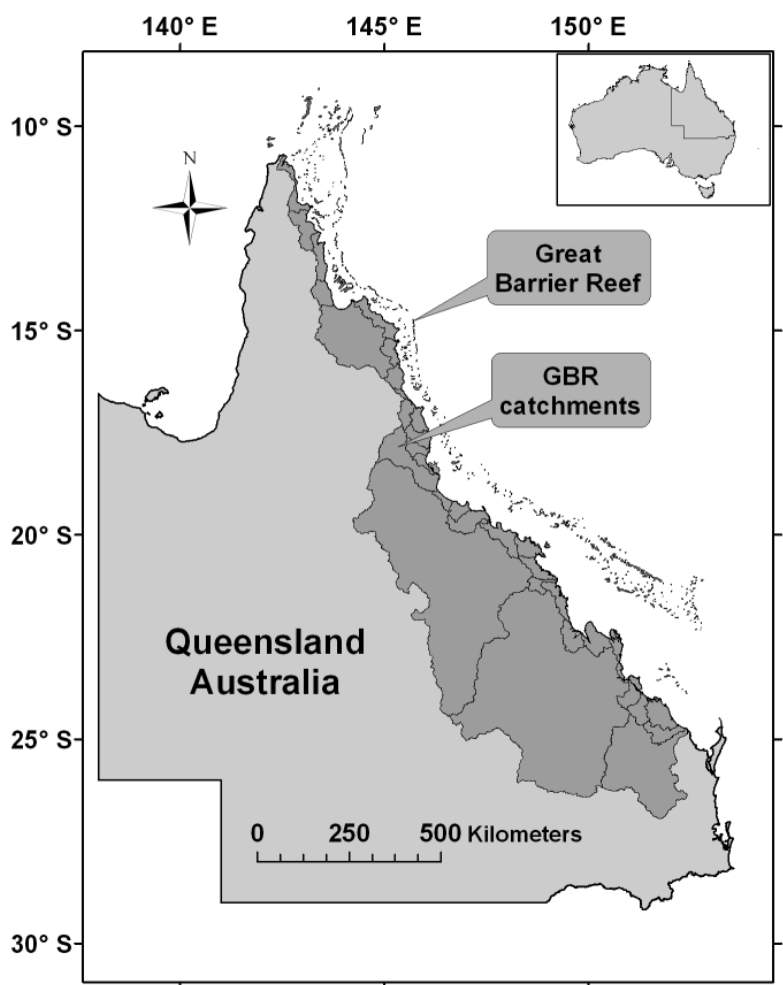

Figure 1. The Great Barrier Reef catchments of northeastern Australia herbicides. Collating and interpreting historic data sets, technical reports and scientific publications, and the collection of new time series concentration data for these constituents in reef catchments was therefore the primary aim of the model validation exercise.

\subsection{Historic Data Sets}

A primary source for long-term water quality data in Queensland is the HYDSTRA database maintained by DERM. The database archives time series ambient (low-flow) and high-flow water quality data acquired from water sampling and probe measurements from hand held and continuous logging equipment. These data were included where available for the GBR catchments.

Other in-house data sets derived from various DERM catchment science projects were also incorporated in the collation exercise. Collaboration and data sharing has been an important source for data housed outside state government agencies. For example, valuable raw data was made available from the Australian Institute of Marine Science, James Cook University and regional natural resource management (NRM) groups. 
Packett et al., Increasing confidence in model prediction:

A key benefit of having access to raw monitoring data (as outlined above) is the ability to then process the data into formats and outputs suitable for the modelling exercise at hand. Taking advantage of existing professional networks and collaboration across research agencies can result in access to valuable data.

In summary, the approach used to collate historic data included:

- Accessing state government databases (in this case the DERM HYDSTRA dbase), including project science data, which may not reside on the main corporate database.

- Approaching research organisations and regional NRM groups for raw monitoring data

- Using existing networks to identify collaboration opportunities in regards to data sharing

\subsection{Available Literature}

Previous modelling reports and papers can provide important reference points for new modelling projects in the same catchment or region. There has been a number of GBR catchment modelling project reports published in recent years and they were incorporated in the current data collation exercise. The reports varied in the degree of confidence placed in the modelled load estimates. In almost all cases however the report authors have detailed where water quality data was available for parameterisation and validation, and where best estimates were used when reliable data was not available (Brodie et al., 2003, McKergow et al., 2005a).

The Short Term Modelling Project (STM) (Cogle et al., 2006, Dougall et al., 2006), applied a version of the SedNet/ANNEX model to a number of the GBR catchments to estimate the end of catchment average annual loads of suspended sediments and dissolved and particulate nitrogen and phosphorus. The modelled estimates of average annual sediment and nutrient loads from the STM project are being used to validate the Source Catchments modelled estimates.

A project was undertaken in 2010 to develop a baseline loads report by reviewing available data from reports, published papers and other sources for best estimates of current average annual loads of suspended sediments, nutrients and pesticides from GBR catchments. This report provided a benchmark for most historical data and was useful for comparing the range of concentrations and loads of constituents of interest to current monitoring data and for model validation (Kroon et al., 2011).

In addition to government agency and research organisation reports a number of regional NRM project reports available in recent times were also utilised. These reports can be the result of regional catchment groups either monitoring water quality via fieldwork or commissioning a consulting group to carry out water quality studies. Valuable data can often be obtained from these reports, particularly for catchments where there has been limited water quality event sampling by other agencies.

Another source of data is consultant's reports. For example Environmental Impact Assessments may be undertaken for proposed developments and background water quality data may have been collected.

A number of scientific papers dealing with studies on estimated loads of sediments, nutrients and pesticides in runoff to the GBR lagoon have been published in recent years and these were incorporated in the collation and validation effort (see references in Kroon et al., 2011, Brodie et al., 2010, Packett et al., 2009)

\subsection{New, Model Specific, Data Collection}

A significant part of the Queensland governments Reef Plan investment is a dedicated GBR wide water quality monitoring Loads Program (action A10 of the Reef Plan). The aim of this program is to provide data for reliable load estimates for suspended sediments, total and speciated nutrients and pesticides to the GBR lagoon from reef catchments. Substantial resources have been allocated to collect times series water samples during (primarily) high flows (when the majority of the annual loads are transported from large dry-tropical catchments) from thirteen major and fifteen sub catchments of the GBR to provide high-resolution time series water quality data.

Catchments with sparse or very limited historical water quality data have been targeted to increase the number of available data sets suitable for load calculation estimates and model validation. DERM gauging stations are the primary sites for water sample collections via manual and automatic sampling methods to allow for paired discharge and concentration measurements that can then be converted to event loads and event mean concentrations (EMC's). This loads monitoring program provides one of the key data sets that will be used for model parameterisation and validation. 
Turbidity has been shown to be an efficient and cost effective, site specific, surrogate for suspended sediment concentration in streams and rivers (Gippel, 1995). A number of the Loads Program sampling sites have been equipped with turbidity probes and setup to record turbidity at regular intervals (for example 20 minute data logging). Water quality analysis data from collected samples can then be compared to turbidity values at the time of sampling and a relationship developed between the two parameters. This relationship can then be used as a high-resolution surrogate for Total Suspended Solids (TSS) and data points between water samples can be in filled with modelled TSS values.

An example of the relationship between turbidity and TSS is shown in Figure 2. Where new data may be required, the use of turbidity probes combined with sampling can provide a, site

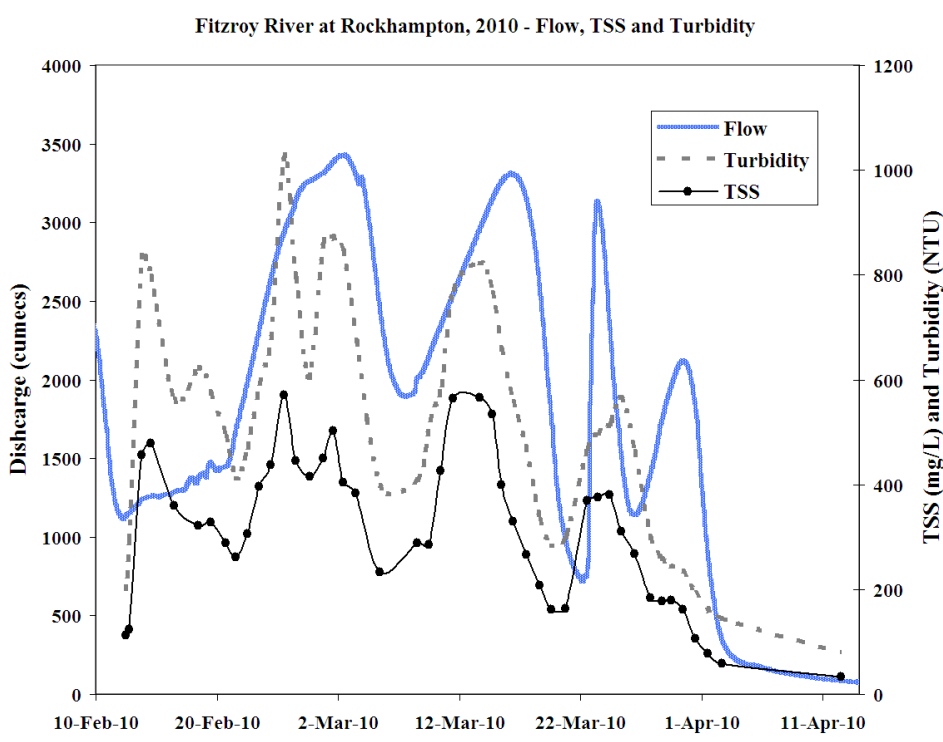

Figure 2. TSS and Turbidity data during the 2010 wet season in the Fitzroy River at Rockhampton, Queensland specific, cost effective method of gaining hi-resolution time-series data for high discharge events. Turbidity probe data collected in the Fitzroy catchment will be used as another source of validation of sediment loads over short timeframes (e.g. monthly).

\subsection{Catchment Processes}

Other data collected to fill knowledge gaps of catchment erosion and deposition processes include cross sectional profile sampling for TSS and the use of Acoustic Doppler equipment to measure the backscatter characteristics of suspended sediments during high flow events. Preliminary results from studies in the Fitzroy River suggest that Acoustic Doppler's could provide a valuable tool to confirm that grab samples taken from the river bank are representative of the cross sectional suspended sediment load.

Sediment particle sizing and storage (dams and weirs) trapping efficiency data has also been collected at a number of dams in the GBR catchments to gain a better understanding of suspended transport in rivers to compare to model outputs and help to identify contributing areas in the landscape (Lewis et al., 2009). Another area of research where data gaps have been identified is the degradation or loss of nutrient and pesticides species in large storages. Preliminary results from pilot programs in non-reef catchments (Waters et al., 2011) will be used to plan similar studies in GBR catchments to improve and refine current models.

Past and current modeling projects have identified gullies as significant sources of sediment. A gullymapping project has been completed in the Fitzroy catchment to help fill gaps in knowledge regarding the extent that gullies contribute sediments in runoff events. This data will be used to help parameterise and validate modelled gully erosion contributions.

While the data collection programs mentioned above may be well outside the available resources of some modelling projects it is worth considering them as useful indicators of what would be considered valuable data collection exercises for complex water quality models. Planning for future modelling applications should include some of the methods described above in parallel with other data collection projects, therefore reducing costs and providing data when it is needed most.

\subsection{Data Processing Software}

Software packages to process time series data and calculate loads were used during the validation exercise. Two useful tools have been developed in recent years to assist with processing raw data.

Firstly, The River Analysis Package (RAP) has been developed by the eWater CRC and is primarily designed for river condition assessments, environmental flow planning and river restoration design. It contains some 
Packett et al., Increasing confidence in model prediction:

useful tools including software applications for hydraulic analysis, time series analysis and time series data management. The package is available at http://www.toolkit.net.au/Tools/RAP .

Secondly, the Loads Tool (incorporated in the Water Quality Analyser), developed by the eWater CRC, is a software tool which can be used to calculate event loads, event mean concentrations (EMC's) and long term loads from a given set of flow and water quality sample data. The software is available at http://www.ewater.com.au/products/ewater-toolkit/eco-tools/water-quality-analyser/ . The Loads Tool was used for load calculations during the validation process.

\section{RESULTS - INTERPRETING THE COLLATED DATA}

For a particular catchment or region, the results of an exhaustive data collation exercise can often be summarised into a simple table or list of values, which represent the bulk of the available data. Depending on the extent and type of estimation (modelled or calculated from sampling) there will be variations in the range of values for constituents. For example, Table 1 lists the average annual load of suspended sediments and total nitrogen and phosphorus (in tonnes) for the Tully River from various sources.

Table 1 An example of summarised estimated annual loads from various sources for the Tully catchment

\begin{tabular}{|l|l|l|l|l|r|r|}
\hline $\begin{array}{c}\text { Estimate type } \\
\text { (EMC's and } \\
\begin{array}{c}\text { monitored data } \mathrm{x} \\
\text { discharge) }\end{array}\end{array}$ & $\begin{array}{c}\text { Source of estimate } \\
\text { or reference data for calculated } \\
\text { estimate }\end{array}$ & $\begin{array}{c}\text { Method } \\
\text { used here }\end{array}$ & $\begin{array}{c}\text { Average } \\
\text { Annual } \\
\text { flow } \\
(\mathrm{ML} / \mathrm{y})\end{array}$ & $\begin{array}{c}\text { Total } \\
\text { Suspended } \\
\text { Solids } \\
(\mathrm{t} / \mathrm{y})\end{array}$ & $\begin{array}{c}\text { Total } \\
\text { Nitrogen } \\
(\mathrm{t} / \mathrm{y})\end{array}$ & $\begin{array}{c}\text { Total } \\
\text { Phosphorus } \\
(\mathrm{t} / \mathrm{y})\end{array}$ \\
\hline Modelled & McKergow et al., (2005a, b) & Reported & & 191,000 & 2,080 & 224 \\
\hline Modelled & Cogle et al., (2006) & Reported & & 132,000 & 2,482 & 1,400 \\
\hline Review of estimates & Kroon et al., (2011) & Reported & & 92,000 & 110 \\
\hline Monitored data & AIMS data (1982 - 1996) & Loads Tool & $3,076,923$ & 95,385 & 1,114 & 92 \\
\hline Monitored data & DERM (2007 to 2009) & Loads Tool & $2,695,382$ & 92,418 & 1,211 & 114 \\
\hline
\end{tabular}

The example above illustrates how estimates can vary substantially depending on the methods used, and this is a data rich catchment in relative terms compared to some GBR regions (for example, Cape York catchments). There will be a higher degree of confidence in some of the estimations listed above compared to others, depending on the data and methods used in the estimation. The previous estimates can therefore be used as a guide for current modelled out puts.

In other words, if the current model produces outputs that are within the range of values in Table 1. there will be a reasonable degree of confidence that the model is performing as expected. Similar tables were prepared for other GBR catchments and regions (combined catchments) where data was scarce for individual catchments. The full list of constituents includes those listed above plus dissolved and particulate nitrogen and phosphorus species, and a range of herbicides. The load estimates derived from monitored data (sampled concentrations $\mathrm{x}$ discharge for a period) will form the primary data set for model validation.

During the course of past and current projects the interrogation of data sets has revealed that there are often significant relationships to be found between constituents. For example, the relationship between TSS and Total Phosphorus (TP) is well known in the Fitzroy catchment and depends on the source of flood water (Packett et al., 2009), as is the relationship between turbidity and TSS. Further, reasonable relationships can exist between TSS and Total Nitrogen, and to a lesser degree often between the dissolved and particulate fractions for total nutrients. These patterns are often regionally specific, for example, differing between wet and dry tropics.

Land use can also affect these relationships within a single catchment; however, it is well worth examining any field data to determine if there are correlations between constituents. For example, if a reliable relationship is observed between TSS and TP in a data set sampled over three years, this relationship could be applied to TSS data in a subsequent year where no TP data is available to produce a range of possible concentrations. Such extrapolations should be applied with caution, however, where no data is available, this method could provide a reasonable estimate of missing values.

\section{DISCUSSION}

While the basic concepts that underpin models of sediment and nutrient movement are relatively well known, the data to validate these models is generally the limiting factor. To overcome this issue, the water quality 
data collation exercise undertaken to parameterise and validate the GBR Source Catchments models utilised a broad range of spatial and temporal data sets. Previous modelling and research projects have highlighted significant data gaps that can decrease the confidence in model outputs, and with each model iteration there has been efforts made to reduce these knowledge gaps.

A key finding of this and previous data collation exercises is the wide range of concentrations observed for constituents such as suspended sediments, nutrients and pesticides in runoff from GBR catchments. Often these variations in concentration can originate from the same catchment due to extremes in climate, ground cover, land use and a number of other contributing factors. Therefore, no single, short-term water quality data set should be considered to representative for long-term applications. This would seem obvious, but there are situations when there is very limited data available to validate models for a particular catchment.

In situations such as these there may be a tendency to apply discreet and extreme concentrations that can confound the validation process. Best estimates, which combine sparse data with regional knowledge, may prove to be more valuable in such cases. The results of current and previous water quality data collation would suggest that developing a range of possible concentrations (annual loads, EMC's, etc) might be a worthwhile approach where data is scarce.

In summary, the current water quality collation and collection effort has provided an opportunity to reevaluate historical data and add to the existing data for increased the confidence in model prediction for GBR catchments.

A common issue with monitoring data used for model parameterisation and validation is that historical data sets can often under represent high discharge conditions. This is because historical data sets often contain many ambient (low flow) and few high flow data points. Ambient data generally tends to be of a lower concentration compared to high flow water quality data. For example TSS concentration in low flow conditions is normally far lower than high flow (flood) concentration.

To address this issue, a dedicated event based water quality monitoring program has been in place for a number of GBR catchments since 2006. Results from the current GBR Loads Monitoring program have highlighted the value of collecting reliable high-resolution event data for reliable load estimates. Therefore, a key recommendation for water quality modelling projects where high flow data sets are under represented would be to implement a similar, loads based, monitoring program for model validation.

\section{CONCLUSIONS AND RECOMMENDATIONS}

Primary conclusions and recommendations from the data collation study to date include:

- Collaboration, networking and data sharing are valuable methods for discovering and acquiring water quality data to inform modelling and other applications.

- The use of turbidity probes in combination with water sample collection can add value to a data set by providing a high-resolution surrogate for TSS and possibly other constituents (TP for example).

- Care should be taken when using discreet short term data sets to validate modelling of long term conditions as the modeled output may be more representative of typical conditions than data from a single extreme event.

- Best estimates of concentration ranges based on local and regional experience may provide a valuable contribution to water quality information where adequate field data is not available.

- The commissioning of a review (report) may be a cost effective and efficient way to provide summaries of existing regional data to inform modelling projects.

- The level of confidence in model outputs experienced by modellers, stakeholders and end users can be significantly increased when the foundations for model parameterisation and subsequent validation consist of defensible water quality data, therefore, a substantial data collation effort should be included when planning a catchment modelling project.

- The data used to validate models is generally the limiting factor. Therefore, to overcome this issue, model validation should aim to utilise literature, expert knowledge, and any raw data available to achieve greater confidence in modelled outputs.

- When data is scarce or non-existent, new data collection (field sampling) should be seriously considered. Dedicated sampling programs during high flow events will produce the most valuable data for loads estimation and model validation and therefore increase the confidence in model prediction. 
Packett et al., Increasing confidence in model prediction:

\section{REFERENCES}

Brodie, J., Waterhouse, J., Lewis, S., Bainbridge, Z. and Johnson, J. (2010) Current loads of priority pollutants discharged from Great Barrier Reef Catchments to the Great Barrier Reef, ACTFR REPORT NUMBER 09/02, Australian Centre for Tropical Freshwater Research, James Cook University, Townsville, Australia http://www-public.jcu.edu.au/actfr/reports/2009/JCUPRD 057072

Brodie, Jon E, McKergow, Lucy A, Prosser, Ian P, Furnas, Miles, Hughes, Andrew O, and Hunter, Heather (2003) Sources of sediment and nutrient exports to the Great Barrier Reef World Heritage Area. Australian Centre for Tropical Freshwater Research, Townsville, Australia.

Cogle, A.L., Carroll, C. and Sherman, B.S., (2006). Editors. The use of SedNet and ANNEX models to guide GBR catchment sediment and nutrient target Setting. Department of Natural Resources, Mines and Water. QNRM06138. http://www.wqonline.info/products/short_term_modelling.html

Dougall, C., Packett, R., Carroll, C., Sherman, B.S., Read, A., Chen, Y. and Brodie, J. (2006) Sediment and nutrient modelling in the Fitzroy NRM region. Volume 5. In: The use of SedNet and ANNEX models to guide GBR catchment sediment and nutrient target setting Ed A.L. Cogle, C. Carroll and B.S. Sherman. Department of Natural Resource, Mines and Water. QNRM06138.

eWater Cooperative Research Centre. (2010). Source Catchments User Guide, eWater Cooperative Research Centre, Canberra. ISBN 978-1-921543-29-6

Gippel, C. J. (1995). Potential of turbidity monitoring for measuring the transport of suspended-solids in streams. Hydrological Processes 9:83-97.

Kroon, J., Kuhnert, P., Henderson, B., Wilkinson, S., Henderson, A., Brodie, J. and Turner, R., (2011) River loads of suspended solids, nitrogen, phosphorus and herbicides delivered to the Great Barrier Reef lagoon (submitted to Marine Pollution Bulletin - special edition)

Lewis, S.E., Sherman, B.S., Bainbridge, Z.T., Brodie, J.E., Cooper, M. (2009). Modelling and monitoring the sediment trapping efficiency and sediment dynamics of the Burdekin Falls Dam, Queensland, Australia. In Anderssen, R.S., R.D. Braddock and L.T.H. Newham (eds) 18th World IMACS Congress and MODSIM09 International Congress on Modelling and Simulation. Modelling and Simulation Society of Australia and New Zealand and International Association for Mathematics and Computers in Simulation, July 2009, pp. 4022-4028. ISBN: 978-0-9758400-7-8. http://www.mssanz.org.au/modsim09/I14/lewis.pdf

McKergow, L. A., Prosser, I. P., Hughes, A. O., and Brodie, J. (2005a). Sources of sediment to the Great Barrier Reef World Heritage Area. Marine Pollution Bulletin 51, 200-211. doi:10.1016/

McKergow, L. A., Prosser, I. P., Hughes, A. O., and Brodie, J. (2005b). Regional scale nutrient modelling: exports to the Great Barrier Reef World Heritage Area. Marine Pollution Bulletin 51, 186-199

Packett, R., Dougall, C., Rohde, K., Noble, R., (2009). Agricultural lands are hot-spots for annual runoff polluting the southern Great Barrier Reef lagoon. Mar. Poll. Bull. 58, 976-986.

State of Queensland and Commonwealth of Australia, (2003). Reef Water Quality Protection Plan; for catchments adjacent to the Great Barrier Reef World Heritage Area. Queensland Department of Premier and Cabinet, Brisbane.

Waters, D., Sliburn, M. and Cook, F., (2011) Calculating nutrient and pesticide decay rates (half life) from long term monitoring data for model parameterisation. (MODSIM 2011 paper submitted)

Wilkinson. S., Henderson, A., Chen, Y., Sherman, B., 2004. SedNet User Guide, Version 2. Client Report, CSIRO Land and Water. Canberra. Available from: www.toolkitnetau/sednet 